\title{
Comparative effectiveness of organic acid complexes in the cultivation of broiler chickens
}

\author{
Anastasia Taldykina ${ }^{1}$, Vladimir Semenyutin ${ }^{1}$, Nikolay Bezborodov $^{1}$, and Victor Eremenko ${ }^{2}$ \\ ${ }^{1}$ Belgorod State University named after V.Ya. Gorin; 1Vavilova Street, Belgorod region, Belgorod district, Maysky \\ village, 308503, Russia; \\ ${ }^{2}$ Kursk State Agricultural Academy named after I.I. Ivanov, 70 Karl Marx Street, Kursk, 305021, Russia.
}

\begin{abstract}
The paper presents the experimental results using organic acid complexes BiSAlTek, Ecacid and NeoTerm in the diet of broiler chickens of the Cobb 500 cross. The study was carried out in the conditions of the scientific poultry factory of Belgorod State University named after V.Ya. Gorin. There were 4 groups of 100 heads each: I-control, II, III and IV-experimental. As the main diet the chickens of all groups received mixed feed corresponding to the growing periods. In addition to the main diet, the chickens of groups II, III and IV in the periods from 1 to 10 days and from 34 to 38 days of life were given BiSAlTek, Ecacid and NeoTerm acidifiers at the rate of 2.5, 0.5 and 1.5 1/t of water, respectively. The use of additives contributed to a significant, relative to the control, increase in the body weight of chickens of groups II, III and IV by $7.7 \% ; 6.8 \%$ and $8.6 \%$, respectively, against the feed cost reduction per $1 \mathrm{~kg}$ of the body weight by $8.3 \% ; 7.7 \%$ and $9.5 \%$.
\end{abstract}

\section{Introduction}

At the present stage of the domestic economy development the problem of safe feeding for the production of environmentally friendly products is becoming ever more urgent. There is an increasing number of enterprises declaring the safety of meat and eggs as their main competitive advantage. In this regard, in industrial poultry farming, veterinary and sanitary measures aimed at protecting farms from the spread of contagious diseases and ensuring their epizootic well-being are particularly important. Hence, the specialists, including through the diet, develop methods and techniques to activate the body's protective forces based on natural immunostimulation and immunocorrection. Since in some cases the technology used does not meet modern conditions, the bird is forced to adapt to stress with a high strain on the physiological systems and energy consumption. At the same time, growth and development are slowed down, the incidence and mortality of livestock increase.

Therefore, feeding is considered as one of the most important factors in obtaining a healthy product. At the same time, it is very important to provide poultry not only with high-quality balanced food, but also with clean drinking water.

Most poultry enterprises face water quality problems: stiffness, microbial insemination, algae and mold in the drinking system, as well as high $\mathrm{pH}$ levels, which contribute to the growth of microflora [1-3].

It should be noted that in addition to the use of water with high $\mathrm{pH}$ level, the development of pathogenic microflora is also facilitated by highly nutritious feed mixtures used in feeding birds thus changing the reaction of the medium in the digestive tract to the alkaline side [4].

At the same time, without the use of high-protein diets, it is impossible to obtain weight products of meat and poultry farming.

Until recently, antibiotics were widely used to suppress pathogenic microflora and stimulate poultry growth. Regular use of the latter led to the development of tolerance of the pathogenic microflora of the gastrointestinal tract of poultry, disrupted intestinal microbiocenosis and contributed to digestive disorder [5-7]. Besides, residual amounts of antibiotics in meat pose a potential danger to humans.

It is possible to normalize intestinal microflora by including acidifying agents in the diet that reduce $\mathrm{pH}$ $[1,8]$. Acidifiers have proven themselves well in the treatment of drinking water thus improving its taste.

Organic acids and their salts are also widely used as a preservative treatment of feed and grain [4]. They minimize the content of vegetative microflora in stored feed and reduce the degree of insect damage.

Today, complexes of organic and inorganic acids are present on the market as additives to the diet. Manufacturers include vegetable extracts, essential oils and fillers based on natural minerals, as well as medium-chain fatty acids.

Additives are produced in liquid or dry form, in the form of organic acids or their salts. Salts are less aggressive and more convenient to use than liquid acids, but they are less effective because they have a reduced concentration of anions [9].

\footnotetext{
* Corresponding author: polevodova89@mail.ru
} 
A number of studies indicate that the combination of organic acids, or organic and inorganic acids, have a more effective effect on the pathogenic microflora than the use of one inorganic acid, since there is a certain synergy in their action, when several acids in a complex complement each other's properties, working at different acidity levels in different parts of the gastrointestinal tract [4].

An important feature of the action of organic acids is the absence of habituation of pathogenic microflora when using them. Therefore, recently, organic acids are considered as an alternative to antibiotics.

The following Russian companies produce acidifiers: AgroSistema, Belfarmakom, TeknoFeed, Rusbio, Mosagrogen, etc.

BiSAlTek acidifier is a liquid additive of LLC TeknoFeed, which represents the combination of organic acids (formic $-30-35 \%$, propionic $-20-24 \%$, acetic acid - in the form of ammonium acetic acid - 30$35 \%$ ), copper $(0.16 \%$ ) and water (up to $100 \%$ ), (figure 1).

\section{Figure 1 - Composition of BiSAltek, \%}

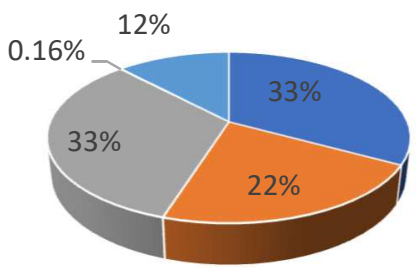

$$
\begin{aligned}
& \text { - formic acid " propionic acid } \\
& \text { " ammonium acetic acid = copper } \\
& \text { - water }
\end{aligned}
$$

Ecacid consists of formic (38-52\%), lactic (3-7\%), orthophosphoric (3.2-7.2\%), citric (1-3\%) acids, ammonium cation (1.1-2.5\%) and water (up to $100 \%$ ), (f igure 2).

Figure 2 - Composition of Ecacid, \%

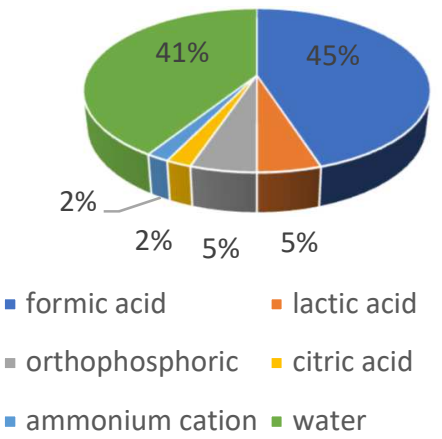

NeoTerm is a complex consisting of succinic acid (30-38 g/l), citric and salicylic acids represented as salts (sodium citrate - 20-30 g/l, sodium salicylate -
15-25 g/l, potassium citrate - 3.5-6 g/l), potassium chloride (1-5 g/l), sorbitol (1.5 g/l), vitamin B6 (0.5-1.5 $\mathrm{g} / \mathrm{l})$ and water $(100 \% \mathrm{~g} / \mathrm{l})$ (figure 3$)$.

\section{Figure 3 - Composition of NeoTerm, g/l}

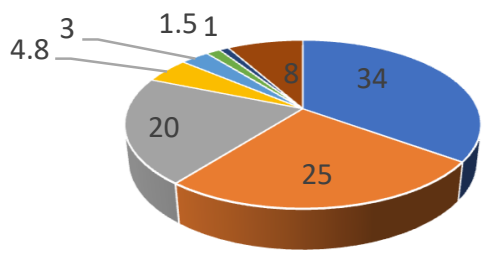

$$
\begin{aligned}
& \text { - succinic acid }=\text { sodium citrate } \\
& \text { - sodium salicylate }=\text { potassium citrate } \\
& \text { - potassium chloride } \text { - sorbitol } \\
& \text { - vitamin B6 }
\end{aligned}
$$

The direct purpose of the BiSAlTek and Ecacid additives is the acidification of water and purification of the watering system. They allow quickly and efficiently reducing and keeping the $\mathrm{pH}$ at a certain level. NeoTerm is intended for the prevention of stresses, including heat, due to succinic acid and salicylates included in its composition [10].

We did not find data in the available literature on the effect of these additives on the growth intensity and preservation of Cobb 500 cross broiler chickens, so the purpose of our research was to study the effect of BiSAlTek, Ecacid and NeoTerm additives on the productivity of broiler chickens of this cross: body weight and preservation.

\section{Materials and Methods}

The subject of the study included broiler chickens of the Cobb 500 cross at the age period of 1-38 days. In the conditions of the educational and scientific poultry factory BelSAU named after V.Ya. Gorin, 4 groups of 100 heads each were formed on the principle of pairs of analogues. As the main diet (MD) the poultry of all groups received compound feed corresponding to the growing periods. In addition to $\mathrm{MD}$, chickens of the group II were given BiSAlTek at a rate of $2.51 / t$ of water, III - Ecacid at a rate of $0.51 / \mathrm{t}$ of water, IV NeoTerm at a rate of $1.5 \mathrm{l} / \mathrm{t}$ of water. The additives were given in cycles from 1 to 10 and from 34 to 38 days.

The body weight of the chickens was controlled by weekly individual weighing on Bat 1 electronic scales (Czech Republic).

Data processing was carried out through at $\mathrm{p} \leq 0.05$.

\section{Results and Discussion}

Body weight is an indicator that reflects the influence of the feeding and maintenance conditions, in which 
animals and birds are raised, as well as the nature and intensity of physiological processes in the body.

Growth rates and other productivity indicators depend on the optimal parameters of the veterinary requirements, including the set and ratio of macro- to micronutrients. At the same time, the correct selection of combinations of organic acids introduced into the body, and optimization of the mode of their introduction play a certain role. Table 1 shows the growth of chickens against the background of the test additives.

Table 1. Growth and body weight dynamics of broiler chickens, $g$

\begin{tabular}{|c|c|c|c|c|}
\hline \multirow{2}{*}{ Age, days } & \multicolumn{3}{|c|}{ Group } \\
\cline { 2 - 5 } & I - K & II & III & IV \\
\hline 1 & $58.0 \pm 0.4$ & $59.0 \pm 0.4$ & $58.4 \pm 0.5$ & $58.3 \pm 0.2$ \\
\hline 8 & $232.0 \pm 2.9$ & $237.0 \pm 2.1$ & $236.4 \pm 3.6$ & $245.8 \pm 1.1^{* * *}$ \\
\hline 15 & $614.5 \pm 10.2$ & $628.3 \pm 5.8$ & $628.0 \pm 8.3$ & $636.2 \pm 4.1^{*}$ \\
\hline 22 & $1193.5 \pm 28.5$ & $1203.6 \pm 11.8$ & $1203.0 \pm 29.0$ & $1231.7 \pm 14.2$ \\
\hline 29 & $1856.7 \pm 44.9$ & $1893.1 \pm 26.0$ & $1889.8 \pm 60.9$ & $1919.6 \pm 27.2$ \\
\hline 38 & $2385.1 \pm 68.8$ & $2567.7 \pm 43.9 *$ & $2548.2 \pm 45.1 *$ & $2590.8 \pm 26.3 * *$ \\
\hline
\end{tabular}

Note: hereinafter $*$ - difference with respect to control group $* \mathrm{p}<0.05 ; * * \mathrm{p}<0.01 ; * * * \mathrm{p}<0.001$.

The dynamics showed that the inclusion of organic acid complexes in the diet had a positive effect (with varying degrees of reliability) on the growth and development of poultry.

Thus, day 8 showed the tendency to body weight increase in the II and III experimental groups relative to the control by $2.2 \% ; 1.9 \%$ and in IV - by $6.0 \%$ $(\mathrm{p}<0.01)$.

On day 15 , the positive dynamics shown by us in favor of chickens of experimental groups remained: in group IV the body weight reliably exceeded the control by $3.5 \%(\mathrm{p}<0.05)$; in II and III - by $2.2 \%(\mathrm{p}>0.05)$.

On day 22, we observed a tendency to increase in body weight in group IV by $3.2 \%$ relative to group I-K; and no changes in group II and III.

In the next period (on the 29th day), the tendency to increase the average live weight was observed in the II, III and IV experimental groups - by 2.0, 1.8 and $3.4 \%$, respectively, relative to the I control group.

By the end of the growing period (day 38), the average chicken weight in group II increased by $7.7 \%$ $(\mathrm{p}<0.05)$, in group III - by $6.8 \%(\mathrm{p}<0.05)$ and in group IV - by $8.6 \%(\mathrm{p}<0.01)$ relative to I-control.

Figure 4 shows the change in the live weight of broiler chickens with age against the background of the use of additives.

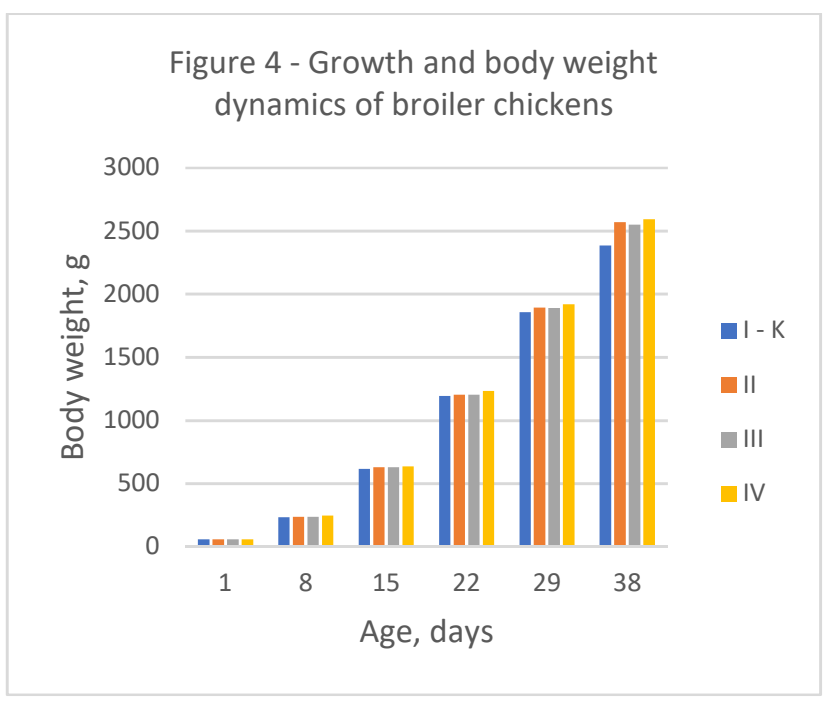

The growth of the body weight is one of the important indicators of the development of farm animals. At the same time, the faster the growing stock grows, the better it pays for food with products. Table 2 shows the values of absolute and average daily increase of the body weight of chickens over 38 days of cultivation.

Table 2. Absolute and average daily chicken growth per experiment, g

\begin{tabular}{|c|c|c|c|c|}
\hline \multicolumn{1}{|c|}{ Indicators } & I - control & II & III & IV \\
\hline $\begin{array}{c}\text { Gain, g: } \\
\text { - absolute }\end{array}$ & $2327.1 \pm 67.5$ & $2508.7 \pm 43.2$ & $2489.8 \pm 79.6$ & $2532.5 \pm 57.1$ \\
\hline in \% to control & 100.0 & 107.8 & 107.0 & 108.8 \\
\hline - average daily & $61.2 \pm 1.8$ & $66.0 \pm 1.1$ & $65.5 \pm 2.1$ & $66.6 \pm 1.5$ \\
\hline in \% to control & 100.0 & 107.8 & 107.0 & 108.8 \\
\hline
\end{tabular}

Table 2 shows that the absolute gain in body weight of chicken in groups II, III and IV was higher than in the control group by $7.8 \%, 7.0 \%$ and $8.8 \%$, respectively.

When broiler chickens are grown under conditions of intensive technology, a serious problem is a decrease in the level of non-specific resistance of the chicken body and their resistance to adverse environmental factors. The use of some additives makes it possible to increase resistance of an organism and, at the same time, to provide increased productivity and preservation of poultry $[8,9]$.

Daily control during the experiment allowed studying the influence of additives on the preservation 
of chickens during the experiment. The obtained data are shown in Table 3.

Table 3. Preservation of broiler chickens

\begin{tabular}{|c|c|c|c|}
\hline Group & $\begin{array}{c}\text { Beginning of } \\
\text { the } \\
\text { experiment, } \\
\text { heads }\end{array}$ & $\begin{array}{c}\text { Number } \\
\text { of dead } \\
\text { birds, } \\
\text { heads }\end{array}$ & $\begin{array}{c}\text { Preservation, } \\
\%\end{array}$ \\
\hline $\begin{array}{c}\text { I - } \\
\text { control }\end{array}$ & 100 & 6 & 94 \\
\hline II & 100 & 2 & 98 \\
\hline III & 100 & 4 & 96 \\
\hline IV & 100 & 2 & 98 \\
\hline
\end{tabular}

Table 3 makes it possible to conclude that the preservation of broiler chickens in groups II, III and IV exceeded that in the control by $4 \%, 2 \%$ and $4 \%$, respectively.

It should be noted that in the process of determining the causes of poultry death loss in experimental groups, no signs of gastrointestinal diseases were found. During their autopsy, only changes corresponding to external compression effects were found, while in the digestive canal the organs of chickens from the control group weakly expressed inflammatory serous or serous-catarrhal changes.

Besides, the chickens of experimental groups showed more pronounced motor activity, good appetite and formed litter, which indicates a positive effect of organic acids on digestion processes. The feather cover in the cloaca area of some chickens of the control group was stained with thinned feces.
Thus, the inclusion of organic acids complexes in the diet of chickens as part of the preparations BiSAlTek, Ecacid and NeoTerm contributed to increased liveability of the bird. In our opinion, this is caused by the decrease in the $\mathrm{pH}$ of the medium that limits the growth of microorganisms that negatively affect the poultry body. In addition, organic acids have a favorable effect on the chicken body. They normalize the $\mathrm{pH}$ medium within the gastrointestinal tract, which contributes to better digestion of feed nutrients, nitrogen, calcium, and phosphorus retention [11] and at the same time prevents the formation of pathogenic microflora in the lower gastrointestinal tract [6].

When raising broiler chickens, the study of feed consumption is important, as one of the primary factors influencing the growth of live weight.

Table 4 shows the feed consumption per unit of production controlled by us during the experiment using various additives.

Table 4 shows that the feed costs per $1 \mathrm{~kg}$ of the body weight increase were within the limits provided by the technology for growing modern crosses of meat poultry [4].

The increase in the body weight of broiler chickens in experimental groups occurred against the background of low feed costs. In particular, feed costs per head in groups II, III and IV decreased relative to the control by $1.3 \%, 1.0 \%$ and $1.3 \%$, respectively, an increase in the growth rate of poultry at a lower feed cost per head led to a decrease in feed costs per unit increase by $8.3 \%, 7.7 \%$ and $9.5 \%$.

Table 4. Feed costs, $\mathrm{kg} / \mathrm{kg}$

\begin{tabular}{|l|c|c|c|c|}
\hline \multirow{2}{*}{ Indicators } & \multicolumn{3}{c|}{ Group } \\
\cline { 2 - 5 } & I - control & II & III & IV \\
\hline $\begin{array}{l}\text { Eaten for the whole period, kg (by } \\
\text { poultry stock) }\end{array}$ & 367.26 & 378.73 & 371.22 & 378.28 \\
\hline Increase in livestock, kg & 224.20 & 251.63 & 244.63 & 253.91 \\
\hline Body weight gain per 1 head, kg & $2.33 \pm 0.07$ & $2.51 \pm 0.04$ & $2.49 \pm 0.08$ & $2.53 \pm 0.06$ \\
\hline Feed consumption per 1 head, kg & 3.91 & 3.86 & 3.87 & 3.86 \\
\hline $\begin{array}{l}\text { Feed consumption per 1 kg of } \\
\text { increase, kg }\end{array}$ & 1.68 & 1.54 & 1.55 & 1.52 \\
\hline $\pm \%$ to control per 1 head & - & 98.7 & 99.0 & 98.7 \\
\hline $\pm \%$ to control per 1 kg increase & - & 91.7 & 92.3 & 90.5 \\
\hline
\end{tabular}

\section{Conclusion}

Feeding of Cobb 500 cross broiler chickens with BiSAlTek, Ecacid and NeoTerm organic acid complexes increased their growth intensity by $7.7 ; 6.8$ and $8.6 \%$ and increased the preservation of livestock by $4 ; 2$ and $4 \%$, respectively. The results are shown against the background of the decrease in feed consumption per head - by $1.3 ; 1.0$ and $1.3 \%$ and per growth unit - by $8.3 ; 7.7$ and $9.5 \%$, respectively.

\section{References}

1. A. Jafarov Feed combination. 5, 64-68, (2010)

2. A.Sh. Kavtarashvili, Poultry farming: scientific and production journal. 3, 17-25, (2013)

3. A.E. Mysyakin, Hygienic assessment of the quality of drinking water at centralized water supply depending on the types of pipes and water use regimes: Ph.D. thesis (Russian State Medical University. Moscow, (2010).

4. V.I. Fisinin, I.A. Egorov, T.M. Okolelova, S.A. Imangulov, Scientific foundations of feeding 
agricultural poultry (Sergiev Posad: VNITIP, 2009).

5. G.F. Bovkun, V. Troshin, N.I. Malik, E.V. Malik, Poultry farming, 6, 25-27, (2005).

6. L.N. Gamko, I.I. Sidorov, L.T. Talyzina, Yu.N. Chernenok Bryansk: BSU. 6, 25-27 (2015)

7. A.A. Grozina Agricultural biology. 6, 45-58, (2014)

8. V. Bannikov, Poultry farming. 3, 40-4, (2007)

9. Yu.A. Ponomarenko, V.I. Fisinin, I.A. Egorov Safety of feed, feed additives and food products: monograph (Minsk: Eco-perspective, 2012).

10. M.S. Naidensky, Feedstuff. 5 (2005)

11. A.A. Taldykina, V.V. Semenyutin Problems of biology of productive animals, 1, 95-100, (2021).

12. V.N. Ageev, Yu.P. Kvitkin, P.N. Pankov, O.D. Sintserova Feeding agricultural poultry (Moscow: Rosselkhozizdat, 1982)

13. G.P. Belekhov, A.A. Chubinskaya Mineral and vitamin nutrition of farm animals (Moscow: State Publishing House of Agricultural Literature, 1960)

14. S.V. Kozhevnikov, S.F. Sukhanova Zootechny. 4, 16-17 (2010)

15. L.I. Podobed, V.A. Fisinin, I.A. Egorov, T.M. Okolelova Fodder and technological violations in poultry farming and their prevention (Odessa: Aquatoria, 2013) 